\title{
Telerehabilitation Versus Standard Care for Improving Cognitive Function and Quality of Life for Adults with Traumatic Brain Injury: a Systematic Review
}

\author{
Samantha Betts \\ University of South Australia, betsm002@mymail.unisa.edu.au \\ Lana Feichter \\ University of South Australia, feily001@mymail.unisa.edu.au \\ Zoe Kleinig \\ University of South Australia, klezj001@mymail.unisa.edu.au \\ Alice O'Connell-Debais \\ University of South Australia, ocoas002@mymail.unisa.edu.au \\ Henry Thai \\ University of South Australia, thahy002@mymail.unisa.edu.au \\ See next page for additional authors \\ Follow this and additional works at: https://nsuworks.nova.edu/ijahsp \\ Part of the Medicine and Health Sciences Commons
}

\section{Recommended Citation}

Betts S, Feichter L, Kleinig Z, O'Connell-Debais A, Thai H, Wong C, et al. Telerehabilitation Versus Standard Care for Improving Cognitive Function and Quality of Life for Adults with Traumatic Brain Injury: a Systematic Review. The Internet Journal of Allied Health Sciences and Practice. 2018 Jan 01;16(3), Article 9.

This Systematic Review is brought to you for free and open access by the College of Health Care Sciences at NSUWorks. It has been accepted for inclusion in Internet Journal of Allied Health Sciences and Practice by an authorized editor of NSUWorks. For more information, please contact nsuworks@nova.edu. 


\title{
Telerehabilitation Versus Standard Care for Improving Cognitive Function and Quality of Life for Adults with Traumatic Brain Injury: a Systematic Review
}

\begin{abstract}
ABSTRACT

Traumatic brain injury (TBI) is the most significant cause of death and severe disability following major trauma within Australia. Populations at risk include young adults aged 15 to 34, older adults, and military personnel. The main form of intervention following traumatic brain injury is rehabilitation, which places a large demand on the healthcare system. Telerehabilitation involves interventions delivered via telecommunication, which can improve accessibility and reduce this burden. There have been no systematic reviews conducted on the effectiveness of telerehabilitation in treating traumatic brain injury.
\end{abstract}

Purpose: To examine the effectiveness of telerehabilitation for adults with traumatic brain injury.

Methods: A systematic search of Medline, Embase, the Cumulative Index of Nursing and Allied Health Literature (CINAHL), Scopus, The Cochrane Library, OTSeeker and Google Scholar was conducted. Studies were included with participants aged 18 to 64 with traumatic brain injury and receiving telerehabilitation interventions. Methodological quality was assessed using the critical appraisal tools: Critical Appraisal Skills Programme (CASP) checklist for randomised controlled trials, and McMaster Critical Review for Quantitative Studies for non-randomised studies.

Results: Three randomised controlled trials, one pseudo-randomised controlled trial, one case-control trial and one pre-post case series were included in this systematic review. Critical appraisal of the included studies revealed overall methodological quality to be moderate. A range of interventions with differing parameters were used as part of telerehabilitation. Collectively, there is some consistent evidence to indicate that telerehabilitation may be equally effective as other forms of care in the delivery of cognitive and psychological interventions, in addressing memory and depressive symptoms for adults with mild to severe traumatic brain injury. However, it is unclear if it is superior to other forms of care.

Conclusions: A small number of studies have investigated the effect of telerehabilitation for adults with traumatic brain injury. The current evidence base is limited due to lack of standardised intervention parameters, outcomes measures and robust sample size. Despite these limitations, telerehabilitation may offer a complementary model of care for adults with traumatic brain injury, especially in instances where traditional models of care may not be readily accessible (such as those in rural and remote areas).

\section{Author Bio(s)}

Samantha Betts is a current third year occupational therapy student at the University of South Australia, Adelaide.

Lana Feichter is a current third year occupational therapy student at the University of South Australia, Adelaide.

Zoe Kleinig is a current third year occupational therapy student at the University of South Australia, Adelaide.

Alice O'Connell-Debais is a current third year occupational therapy student at the University of South Australia, Adelaide.

Henry Thai is a current third year occupational therapy student at the University of South Australia, Adelaide. 
Carmen Wong is a current third year occupational therapy student at the University of South Australia, Adelaide.

Saravana Kumar, BAppSc (Physio), MPT (Manipulative and Sports), PhD, is a senior lecturer at the School of Health Sciences, Sansom Institute for Health Research, University of South Australia, Adelaide. He is a registered Physiotherapist in Australia.

\section{Authors}

Samantha Betts, Lana Feichter, Zoe Kleinig, Alice O'Connell-Debais, Henry Thai, Carmen Wong, and Saravana Kumar 


\title{
TUAHSP \\ The Internet Joưnal of Allied Health Sciences and Practice
}

Dedicated to allied health professional practice and education

Vol. 16 No. 3 ISSN 1540-580X

\section{Telerehabilitation Versus Standard Care for Improving Cognitive Function and Quality of Life for Adults with Traumatic Brain Injury: a Systematic Review}

\author{
Samantha Betts \\ Lana Feichter \\ Zoe Kleinig \\ Alice O'Connell-Debais \\ Henry Thai \\ Carmen Wong \\ Saravana Kumar
}

University of South Australia

Australia

\begin{abstract}
Background: Traumatic brain injury (TBI) is the most significant cause of death and severe disability following major trauma within Australia. Populations at risk include young adults aged 15 to 34, older adults, and military personnel. The main form of intervention following traumatic brain injury is rehabilitation, which places a large demand on the health care system. Telerehabilitation involves interventions delivered via telecommunication, which can improve accessibility and reduce this burden. There have been no systematic reviews conducted on the effectiveness of telerehabilitation in treating traumatic brain injury. Purpose: The purpose of the study was to examine the effectiveness of telerehabilitation for adults with traumatic brain injury. Methods: A systematic search of Medline, Embase, the Cumulative Index of Nursing and Allied Health Literature (CINAHL), Scopus, The Cochrane Library, OTSeeker, and Google Scholarwas conducted. Studies were included with participants aged 18 to 64 with traumatic brain injury and receiving telerehabilitation interventions. Methodological quality was assessed using critical appraisal tools: Critical Appraisal Skills Programme (CASP) checklist for randomized controlled trials and McMaster Critical Review for Quantitative Studies for nonrandomized studies. Results: Three randomized controlled trials, one pseudo-randomized controlled trial, one case-control trial, and one pre-post case series were included in this systematic review. Critical appraisal of the included studies showed overall methodological quality to be moderate. A range of interventions with differing parameters were used as part of telerehabilitation. Collectively, there was some consistent evidence to indicate that telerehabilitation may be equally effective as other forms of care in the delivery of cognitive and psychological interventions in addressing memory and depressive symptoms for adults with mild to severe traumatic brain injury. However, it is unclear if it is superior to other forms of care. Conclusions: In a small number of studies, the effect of telerehabilitation for adults with traumatic braininjury has been investigated. The currentevidence base islimitedduetolack ofstandardizedintervention parameters, outcomes measures, and robust sample size. Despite these limitations, telerehabilitation may be a complementary model of care for adults with traumatic brain injury, especially in instances in which traditional models of care may not be readily accessible (such as those in rural and remote areas).
\end{abstract}

Keywords: traumatic brain injury (TBI), telerehabilitation, telehealth, cognitive, memory, quality of life, depressive.

\section{BACKGROUND}

A traumatic brain injury (TBI) is defined as an alteration in brain function or other evidence of brain pathology, caused by an external force, including the head being struck or striking an object, undergoing rapid acceleration or deceleration movement, a foreign body penetrating the brain, or forces from blasts or explosions. ${ }^{1}$ In Australia, TBI is the most significant cause of death and severe 
disability following major trauma and has an estimated annual hospital cost of AU $\$ 184$ million. ${ }^{2}$ High-risk populations for TBI include young adults aged 15 to 34 (increased likelihood of risk-taking and motor vehicle accidents), older adults (increased falls risk), and military personnel (exposure to explosive devices and suicide terrorist attacks) ${ }^{2-4}$

A traumatic brain injury will result in diffuse damage, most commonly affecting the frontal and temporal lobes, producing varied cognitive and behavioral deficits, according to the location and severity of damage..$^{5} \mathrm{~A}$ plethora of consequences may follow, including seizures; headaches; cognitive impairments in memory, attention, decision making, and communication or behavioral changes (emotional dysregulation, apathy, and aggression); and sensory processing issues.6, 7 TBI can be diagnosed based on loss of consciousness as indicated by the Glasgow Coma Scale (GCS) and length of post-traumatic amnesia. ${ }^{8}$ The diagnostic criteria for mild TBI is a GCS score of 13 to 15 and post-traumatic amnesia up to 24 hours while the diagnosis for a moderate TBI requires a GCS score of 9 to 12 and post-traumatic amnesia between 1 to 7 days. ${ }^{8}$ The diagnostic criteria for severe TBI is a GCS score of 3 to 8 , and post-traumatic amnesia greater than seven days. ${ }^{8}$ Of individuals with severe TBI, $39 \%$ die as a result of their injury while $60 \%$ demonstrate poor outcomes as measured by the Glasgow Outcome Scale. ${ }^{4}$

Rehabilitation is an important component of TBI due to the nature of the injury and ongoing disability. Standard TBI rehabilitation includes retraining in activities of daily living, cognitive and behavioral therapies, assistance with community integration and return to work, and carer education. ${ }^{9}$ Within this context, telerehabilitation or telehealth interventions utilize telecommunication and information systems to deliver clinical care to patients from a distance may have a role to play. ${ }^{10}$ In South Australia, medical and allied health practitioners and nurses can deliver telerehabilitation. ${ }^{11}$ There is some evidence to suggest telerehabilitation can improve health care accessibility, especially for those who have limited access to services due to geographical location, affordability, or physical and cognitive impairments. ${ }^{10}$ However, despite its widespread popularity, to date, there remain gaps in knowledge about the impact of telerehabilitation on outcomes, such as cognitive function and quality of life for those with TBI. Therefore, it is timely to update the current body of evidence for clinical practice and improve health care.

\section{METHODS}

\section{Search Strategy}

The methodology of this systematic review was underpinned by Preferred Reporting Items for Systematic Reviews and MetaAnalyses (PRISMA) statement and registered with PROSPERO (CRD42017073730). ${ }^{12}$ In August 2017, a search of 7 electronic databases was conducted with each database being searched independently by two researchers to ensure validity of the search strategy. The databases searched included Medline, Embase, Cumulative Index of Nursing and Allied Health Literature (CINAHL), Scopus, the Cochrane Library, OTSeeker, and Google Scholar. Only studies published in English and about humans were included. No date restrictions were applied as there were no known published systematic reviews. Table 1 presents the participantintervention-comparator-outcome (PICO) criteria. Appendix 1 presents an example of the search terms, limits, and specifications utilized from the database Medline. Grey literature was investigated by conducting a Google search. Pearling of the reference lists of included studies was completed to investigate any further eligible studies that were not located through the database search. Relevant content experts (such as Professors Charles Bombardier, Michelle Bourgeois, Sureya Dikmen and Nancy Temkin) were contacted as means of identifying additional studies relevant to the research question, which had not been discovered through traditional searching.

\begin{tabular}{|c|c|c|c|}
\hline Participant & Intervention & Comparator & Outcome \\
\hline Adults with TBI & Telerehabilitation & Standard Care & $\begin{array}{c}\text { Including, but not limited to, cognitive function and quality } \\
\text { of life }\end{array}$ \\
\hline
\end{tabular}

\section{Study Design}

All forms of primary (quantitative) and secondary evidence were searched for, including systematic reviews (as means of identifying any additional relevant studies), randomized control trials (RCTs), controlled clinical trials (CCTs), and case studies.

\section{Population}

Studies were included if the participants were adults, aged 18 to 64 years, and experiencing any severity of TBI (mild to severe). As TBI in children can require a different management approach due to biological, psychological, and social factors, children were excluded. Older adults who were above the age of 65 years with TBI were excluded due to different variability in the demographic variables and its impact on intervention and outcome parameters. 


\section{Intervention}

Studies were included if the intervention described included telerehabilitation that was delivered through phone, radio, videoconferencing, or online computer messaging programs. Studies were excluded if the intervention referred to telerehabilitation used for case conferencing, assessment, or a co-intervention. Other types of technology used for rehabilitation, such as virtual reality, personal digital assistants or computer programs that deliver therapy without the direct input of a therapist, were also excluded.

\section{Comparator}

Studies that utilized the comparator of standard care were included. Standard care refers to any form of in-person treatment or rehabilitation that does not involve the use of telerehabilitation. Standard therapy intervention for clients with TBI for psychosocial, behavioral, and emotional impairments can include education, peer mentoring, goal-directed therapy, physical activity, skills training and cognitive-behavioral therapy. ${ }^{13}$ Comparators that were excluded included other forms of management of TBI (such as pharmaceutical) or when technology was used merely a tool as part of standard care (such as case conferencing using phone, radio, and video-conferencing).

\section{Outcome Measures}

Studies were included if they used outcome measures that were used to assess cognitive functioning, specifically memory function, through questionnaires, such as the Neurobehavioural Functioning Inventory (NFI) and the Assessment of Neuropsychological Status (RBANS). ${ }^{14,15}$ Studies were also included if they used outcome measures to assess quality of life, such as the EuroQol (EQ5D). ${ }^{16}$ In some instances, depressive symptoms were considered as a proxy measure of quality of life and were measured through assessments, such as the Hamilton Depression Rating Scale (HAMD-17). ${ }^{17}$ Outcomes that were excluded were those used to explore the cost-benefits of telerehabilitation, accessibility, and remuneration of services as the aim of this review was to explore direct client outcomes rather than feasibility of the intervention. Additionally, any research in which qualitative data were reported was excluded.

\section{Study Selection}

A protocol for the systematic review was developed to guide the process of searching and reviewing the literature. Following the database searches, duplicates were removed and a title and abstract review was completed independently by two researchers to determine applicability of the PICO criteria. Each relevant study was then read in full text independently by two researchers to determine inclusion in the review. When disagreements arose throughout this process, the issue was brought to the group of researchers for discussion and majority voting for inclusion or exclusion of the study. Any reasons for exclusion were recorded.

\section{Risk of Bias}

Each researcher independently assessed each included study for methodological quality. The hierarchy of evidence for all the studies was assessed according to the National Health and Medical Research Council (NHMRC) designation of levels of evidence..$^{18} \mathrm{~A}$ modified Critical Appraisal Skills Programme (CASP) was utilized to assess risk of bias for RCTs. ${ }^{19}$ The CASP was modified to generate a numerical score, with yes for 1 and no or can't tell for 0 . Studies could be awarded a minimum score of 0 or maximum score of 9 . Questions 7 and 8 were removed as a subjective response was required as opposed to an objective yes or no response. Additionally, in order to account for placebo bias, studies received a 0 score for question 4 if the researchers were blinded but participants and health professionals were not. A modified McMasters Critical Appraisal Tool (CAT) was used to generate a numerical score for non-randomized quantitative studies with yes for 1 and no, not applicable, or not addressed for $0 .{ }^{20}$ Utilizing the McMasters CAT, studies could receive a minimum score of 0 and a maximum score of $14 .{ }^{20}$ Questions 3 and $4 a$ were not scored as the study design and number of participants were required to be reported. The critical appraisal scores for each study were calculated into percentages to enable comparison.

\section{Data Extraction}

Data from the included studies were extracted by the researchers and collated into a table to gather information on the study design, participants' information (age, sex, and diagnosis), intervention type and duration, comparators (if applicable), outcome measures, and main findings. Given the heterogeneous nature of the included studies, a meta-analysis was not possible. Instead, a narrative synthesis was undertaken.

\section{Data Synthesis}

The NHMRC body of evidence framework was utilized to aid in the interpretation of findings and the implications for clinical practice. The studies were evaluated through the framework of five dimensions of evidence, including (1) quantity, quality, and level of evidence; (2) consistency; (3) clinical impact; (4) generalizability; and (5) applicability to the Australian health care setting. ${ }^{18}$ Applicability to the Australian setting was not included for this review as the findings may be relevant to a broader, international population. 


\section{RESULTS}

\section{Search Results}

A total of 764 articles were found with the search strategy. After the removal of duplicates, first through EndnoteTM and then CovidenceTM, 301 articles underwent title and abstract screening. From this screening, 81 articles were reviewed in full text, which resulted in a final tally of 6 eligible articles. Potentially relevant studies that fulfilled initial inclusion criteria were subsequently excluded for the following reasons: (1) intervention included virtual reality; (2) the participants' age range did not meet the inclusion criteria of 18 to 64 years, and the results were not separated by age; (3) outcome measures did not assess cognitive functioning or quality of life; (4) not an experimental research design; and (5) full-text article not published in English.

Figure 1. PRISMA Flow Diagram
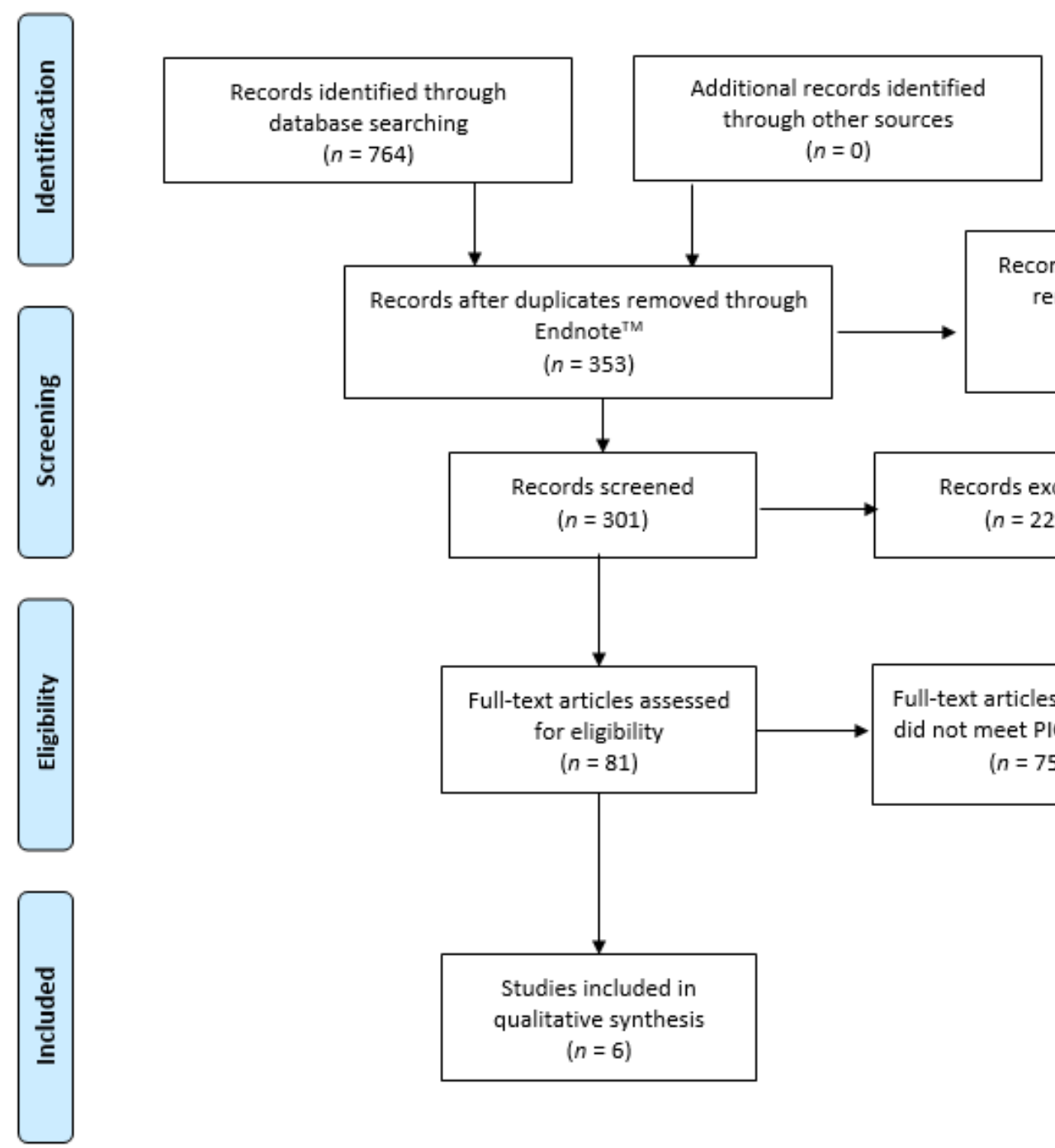

Records after duplicates removed through Endnote $^{\mathrm{TM}}$

$(n=353)$

Records after duplicates removed through Covidence $^{\text {TM }}$ $(n=52)$

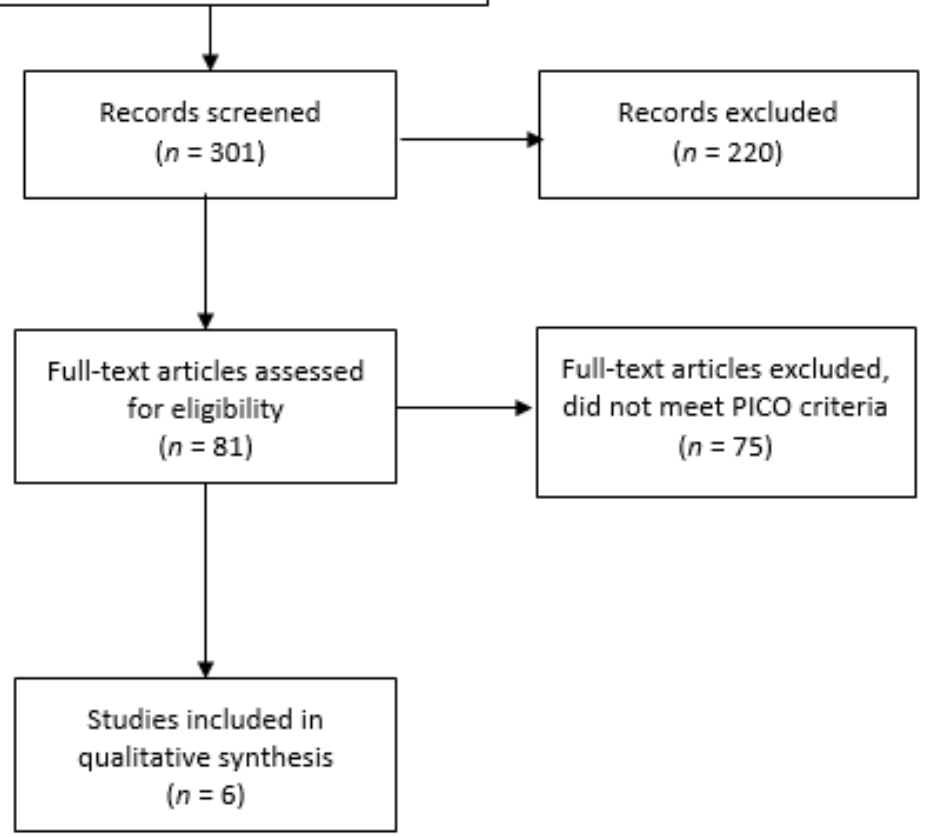

From: Moher, D, Liberati A, Tetzlaff J, Altman DG, The PRISMA Group. (2009). Preferred Reporting Items for Systematic Reviews and Meta-Analyses. The PRISMA Statement. PLoS Med 6(7):e1000097. doi:10.1371/journal.pmed1000097

\section{Ranking and Methodological Quality}

Studies included within this systematic literature review were assessed using a modified CASP RCT, modified McMasters CAT for non-randomized quantitative studies, and the NHMRC dimensions of evidence. ${ }^{18-20}$ Using the NHMRC hierarchy of evidence, 3 studies were classified as RCTs, therefore, ranking as level II. ${ }^{21-23}$ One pseudo-RCT was ranked as III-1, one case-control study ranked as level III-2, and a pre-post case series ranked as a level IV. ${ }^{24-26}$ 
The critical appraisal scores are presented in Tables 2 and 3 and presented some variability among the included studies. The methodological quality of the studies may have been compromised by the risk of placebo bias due to a lack of blinding of patients and health professionals within the studies (which is to be expected given the nature of the intervention). The randomization of intervention and control groups minimizes the allocation bias; however, lack of blinding may give rise to placebo and Hawthorne effect. One study was subjected to potential allocation bias due to randomization of the first 9 participants and, thereafter, instituting a "choice- or equipoise-stratified" approach to selection. ${ }^{24}$ While this approach does present with ecological validity benefits that stimulates the natural real-life setting in which clients would be presented with choice of TBI treatments, the risk of allocation bias became heightened with this approach. Sampling bias was observed in one study in which the trial patients were all recently discharged from the same inpatient rehabilitation unit, ${ }^{23}$ and it was unclear which, if any, sampling framework was used during the recruitment process. Other common methodological concerns included lack of justification of sample size, lack of information on clinical significance, and absence of data about statistical significance for all outcomes. ${ }^{25}$

Table 2. Summary of Critical Appraisal for Randomized Controlled Trials

\begin{tabular}{|c|c|c|c|c|}
\hline Critical appraisal skills program for randomized controlled trials ${ }^{19}$ & Bell et al. ${ }^{21}$ & Bombardier et al. ${ }^{23}$ & Fann et al. ${ }^{24}$ & $\begin{array}{c}\text { Bergquist } \\
\text { et al. }{ }^{22}\end{array}$ \\
\hline Q1: Did the trial address a clearly focused issue? & 1 & 1 & 1 & 1 \\
\hline Q2: Was the assignment of patients to treatments randomized? & 1 & 1 & 1 & 1 \\
\hline $\begin{array}{l}\text { Q3: Were all of the patients who entered the trial properly accounted } \\
\text { for at its conclusion? }\end{array}$ & 1 & 1 & 1 & 0 \\
\hline $\begin{array}{l}\text { Q4: Were patients, health workers, and study personnel "blind" to } \\
\text { treatment? }\end{array}$ & 0 & 0 & 0 & 0 \\
\hline Q5: Were the groups similar at the start of the trial? & 1 & 0 & 1 & 1 \\
\hline $\begin{array}{l}\text { Q6. Aside from the experimental intervention, were all the groups } \\
\text { treated equally? }\end{array}$ & 1 & 1 & 0 & 1 \\
\hline \multicolumn{5}{|l|}{ Q7: How large was the treatment effect? } \\
\hline \multicolumn{5}{|l|}{ Q8: How precise was the estimate of the treatment effect? } \\
\hline Q9. Can the results be applied in your context? & 1 & 0 & 0 & 1 \\
\hline Q10: Were all clinically important outcomes considered? & 1 & 1 & 1 & 1 \\
\hline Q11: Are the benefits worth the harms and costs? & 1 & 1 & 1 & 1 \\
\hline Total score out of 9 & $8 / 9$ & $6 / 9$ & $6 / 9$ & $7 / 9$ \\
\hline Total score in \% & $88.9 \%$ & $66.7 \%$ & $66.7 \%$ & $77.8 \%$ \\
\hline
\end{tabular}

Note: Scores: Yes $=1$, No $=0$, Can't tell $=0 .{ }^{*}$ Questions $8 \& 9$ did not require a score to be allocated.

Table 3. Summary of Critical Appraisal for Non-Randomized Controlled Trials

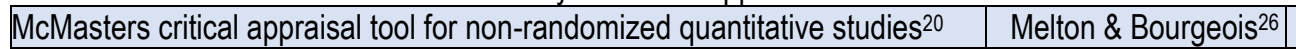

Q1: Was the purpose stated clearly?

Q2: Was relevant background literature reviewed?

Q3: What was the study design?

Q4a: $N=$

Q4b: Was the sample described in detail?

Q4C: Was the sample size justified?

Q5a: Were the outcome measures reliable?

Q5b: Were the outcome measures valid?

Q6a: Intervention was described in detail?

Q6b: Contamination was avoided?

Q6c: Cointervention was avoided?

Q7a: Results were reported in terms of statistical significance?

Q7b: Were the analysis method(s) appropriate?

Q7c: Clinical importance was reported?

Q7d: Drop-outs were reported?

Q8: Conclusions were appropriate given study methods and results

Total score out of 14

Total score in \%

\begin{tabular}{|c|c|}
\hline Melton \& Bourgeois 26 & Reigler et al25 \\
\hline 1 & 1 \\
\hline 1 & 1 \\
\hline & \\
\hline 1 & 1 \\
\hline 0 & 0 \\
0 & 1 \\
\hline 1 & 1 \\
0 & 1 \\
\hline 0 & 0 \\
\hline 0 & 0 \\
\hline 0 & 1 \\
\hline 1 & 1 \\
\hline 1 & 0 \\
\hline 0 & 0 \\
\hline $6 / 14$ & 0 \\
\hline $42.9 \%$ & $8 / 14$ \\
\hline & $57.1 \%$ \\
\hline
\end{tabular}

Note: Scores: $Y e s=1, \mathrm{No}=0$, Not addressed $=0, \mathrm{~N} / \mathrm{A}=0$. 


\section{Study Characteristics}

The studies included in this review were published from 2005 to 2015 and were all conducted in the United States. They consisted of three randomized controlled trials, one pseudo-randomized controlled trial, one case-control trial, and one pre-post case series. ${ }^{21-26}$

\section{Participant Characteristics}

Table 4 presents the characteristics of each study. With regard to gender, there were 2 studies that included $75 \%$ males and $25 \%$ females while another 2 studies included $50 \%$ males and $50 \%$ females. ${ }^{21-23,26}$ When analyzing the age of participants, 2 studies only indicated the age range of participants. When comparing the ages of participants across the 6 studies, it was found that the average age across 5 of the studies was between 31 to 44 years ${ }^{21-23,25-26}$ while one study merely indicated that the participants were above 18 years old. ${ }^{24}$

\section{Types of Intervention}

While there was some consistency with regard to the intervention parameters, there were also differences. With relation to the type of intervention, telephone calls were used in 4 studies as the mode of intervention. ${ }^{21,23-24,26}$ Riegler et al ${ }^{25}$ employed the use of an online treatment program and videophone sessions while Bergquist et al ${ }^{22}$ adopted the intervention of instant messaging sessions over the Internet with a therapist to trial a calendar and diary system. Fann et al24 included three experimental groups: cognitivebehavior therapy (CBT) by telephone, CBT in-person, and standard care. With regard to the frequency of contact, 2 of the studies that had telephone calls as their intervention indicated that they had 6 to 7 telephone calls or sessions over the study period. ${ }^{23,25}$ In terms of the duration of the telephone calls, only 2 studies indicated the duration of the call, and it lasted approximately 30 minutes each. 23,26

\section{Types of Outcomes}

The primary focus of the outcomes presented in the included studies was on cognitive functioning and depressive symptoms. Melton and Bourgeois ${ }^{26}$ utilized non-standardized measures of memory training goal mastery, generalization and goal maintenance while Bergquist et al. ${ }^{22}$ utilized standardized outcome measures, such as the RBANS, NFI, Community Integration Questionnaire (CIQ), and the Compensation Techniques Questionnaire (CTQ), in order to explore memory functioning, use of compensatory strategies, and improvements in memory and mood. Riegler et al explored the effect of Web-based videophone cognitive intervention on memory and learning and utilized Test of Memory and Learning, 2e (TOMAL-2), as the outcome measure. ${ }^{25}$

However Bell et al utilized diverse outcome measures, including the Functional Independence Test (FIM), Disability Rating Scale (DRS), Participation with Recombined Tools-Objective, the Glasgow Outcome Scale (extended), EQ-5D, Short Form-12 Health Survey, Brief Symptom Inventory-18, and Perceived Quality of Life. ${ }^{21}$ Bombardier et al ${ }^{23}$ and Fann et al ${ }^{24}$ explored outcomes relating to depressive symptoms through the use of depression severity on the HAMD-17, the Symptom Checklist- 20 (SCL-20), ${ }^{23}$ Brief Symptom Inventory-Depression (BSI-D), NFI-Depression (NFI-D), and the Mental Health Index (MHI-5), ${ }^{24}$ respectively. 
Table 4. Study Characteristics.

\begin{tabular}{|c|c|c|c|c|c|c|c|c|c|}
\hline Study & $\begin{array}{l}\text { Research } \\
\text { Design }\end{array}$ & $\begin{array}{l}\text { Level of } \\
\text { Evidence } \\
\text { (NHMRC) }\end{array}$ & $\begin{array}{c}\text { CAT } \\
\text { Score (\%) }\end{array}$ & $n$ & $\begin{array}{l}\text { Participant type } \\
\text { and age (years) }\end{array}$ & Intervention & Comparators & $\begin{array}{l}\text { Outcome } \\
\text { measures }\end{array}$ & Main findings \\
\hline Bell et $\mathrm{al}^{21}$ & RCT & II & $88.9 \%$ & 433 & $\begin{array}{l}323 \text { males }(75 \%) \text {, } \\
110 \text { females } \\
\text { ( } 25 \%,>16 \text { years } \\
\text { old, average of } \\
39 \text { years). } \\
\text { Participants were } \\
\text { diagnosed with } \\
\text { mild to severe } \\
\text { TBI. }\end{array}$ & $\begin{array}{l}12 \text { sessions of } \\
\text { scheduled } \\
\text { telephone } \\
\text { intervention } \\
\text { (STI) for brief } \\
\text { training in } \\
\text { problem } \\
\text { solving, } \\
\text { education or } \\
\text { referral. }\end{array}$ & Standard care & $\begin{array}{c}\text { FIM, DRS, } \\
\text { GOS-E, } \\
\text { PART-O, } \\
\text { EQ-5D, } \\
\text { PQOL, } \\
\text { SF-12, } \\
\text { BSI-18. }\end{array}$ & $\begin{array}{l}\frac{\text { Quality of life, }}{\text { functional status }} \\
\text { and global } \\
\text { outcome } \\
p=.987 \\
\text { regression } \\
\text { for year } 1, \\
p=.983 \text { for year } \\
2\end{array}$ \\
\hline $\begin{array}{c}\text { Bergquist } \\
\text { et al }\end{array}$ & $\begin{array}{l}\text { Cross- } \\
\text { over } \\
\text { RCT }\end{array}$ & II & $77.8 \%$ & 14 & $\begin{array}{l}7 \text { males ( } 50 \%, \\
\text { average of } 48 \\
\text { years old, age } \\
\text { range: } 22 \text { to } 61 \\
\text { years). } \\
\text { Participants were } \\
\text { diagnosed with } \\
\text { moderate to } \\
\text { severe TBI. }\end{array}$ & $\begin{array}{l}30 \text { sessions of } \\
\text { online instant } \\
\text { messaging } \\
\text { (IM) } \\
\text { with therapist } \\
\text { trialing a } \\
\text { calendar } \\
\text { system, } \\
30 \text { sessions of } \\
\text { online IM with } \\
\text { a therapist } \\
\text { trialing } \\
\text { the control } \\
\text { diary } \\
\text { intervention. }\end{array}$ & No comparator & $\begin{array}{c}\text { NFI, CIQ, } \\
\text { CTQ. }\end{array}$ & $\begin{array}{l}\text { Memory } \\
\text { NFI: memory } \\
\text { (family } \\
\text { rated) } p=.04 \\
\text { NFI: memory } \\
\text { (patient rated) } p \\
>.05 \\
\text { CTQ: notes in } \\
\text { calendar } p=.02 \\
\text { CTQ: uses cue } \\
\text { card } p=.01 \\
\text { Depressive } \\
\text { symptoms } \\
\text { NFI: depression } \\
\text { (family rated) } p \\
=.02 \\
\text { NFI: depression } \\
\text { (patient rated) } p \\
>.05\end{array}$ \\
\hline
\end{tabular}




\begin{tabular}{|c|c|c|c|c|c|c|c|c|c|}
\hline $\begin{array}{l}\text { Bombardier } \\
\text { et } \mathrm{al}^{23}\end{array}$ & RCT & II & $66.7 \%$ & 171 & $\begin{array}{l}94 \text { males }(75 \%), \\
36 \text { females }(25 \% \text {, } \\
\text { average of } 36 \\
\text { years). } \\
\text { Participants were } \\
\text { diagnosed with } \\
\text { complicated mild } \\
\text { to severe TBI. }\end{array}$ & $\begin{array}{l}7 \times 30-45 \text { min } \\
\text { scheduled } \\
\text { telephone } \\
\text { sessions to } \\
\text { discuss current } \\
\text { concerns, } \\
\text { provide } \\
\text { information, } \\
\text { and } \\
\text { facilitate } \\
\text { problem } \\
\text { solving } \\
\text { relevant } \\
\text { to TBI } \\
\text { recovery. }\end{array}$ & Standard care & $\begin{array}{l}\text { BSI-D, } \\
\text { MHI-5, } \\
\text { NFI-D. }\end{array}$ & $\begin{array}{l}\frac{\text { Depressive }}{\text { symptoms }} \\
\text { BSI-D (raw) } p= \\
.003 \\
\text { BSI-D (T } \\
\text { scores) } p=.017 \\
\text { NFI-D subscale } \\
\text { score } \\
p=.02 \\
\text { MHI-5 } p=.009\end{array}$ \\
\hline Fann et $\mathrm{al}^{24}$ & $\begin{array}{l}\text { Pseud } \\
\text { o-RCT }\end{array}$ & III-1 & $66.7 \%$ & 100 & $\begin{array}{l}37 \text { females } \\
(37 \%), 63 \text { males } \\
(63 \% \text {, age > } 18 \\
\text { years old). } 69 \\
\text { participants were } \\
\text { diagnosed with } \\
\text { complicated mild/ } \\
\text { moderate TBI } \\
\text { while } 31 \\
\text { participants were } \\
\text { diagnosed with } \\
\text { severe TBI. }\end{array}$ & $\begin{array}{l}12 \times 30-60 \text { min } \\
\text { sessions of } \\
\text { cognitive } \\
\text { behavioral } \\
\text { therapy } \\
\text { administered } \\
\text { over } \\
\text { the telephone } \\
\text { (CBT-T) or in- } \\
\text { person (CBT- } \\
\text { IP). }\end{array}$ & Standard care & $\begin{array}{l}\text { HAMD-17, } \\
\text { SCL-20, } \\
\text { Major } \\
\text { Depressive } \\
\text { Disorder } \\
\text { criteria } \\
\text { based } \\
\text { on the } \\
\text { SCID, } \\
\text { Scale, SF- } \\
\text { 36, } \\
\text { Sheehan } \\
\text { Disability } \\
\text { Scale, } \\
\text { Head Injury } \\
\text { Symptom } \\
\text { Checklist. }\end{array}$ & $\begin{array}{l}\text { Depressive } \\
\text { symptoms } \\
\text { HAMD-17 } \\
p=.37 \\
\text { SCL-20 } p=.074 \\
\text { On follow-up: } \\
\text { SCL-20 } p=.043 \\
\text { (SCL-20 scores } \\
\text { for completers } \\
\text { of } 8 \text { or more } \\
\text { CBT sessions } p \\
=.011 \\
\text { Self-reported } \\
\text { symptom } \\
\text { improvement } p \\
=.010 \\
\text { Satisfaction with } \\
\text { depression care } \\
p<.001\end{array}$ \\
\hline $\begin{array}{c}\text { Melton \& } \\
\text { Bourgeois }^{26}\end{array}$ & $\begin{array}{l}\text { Pre-post } \\
\text { case } \\
\text { series }\end{array}$ & IV & $42.9 \%$ & 7 & $\begin{array}{l}3 \text { males (42.9\%), } \\
4 \text { females } \\
\text { ( } 57.1 \%, 33-56 \\
\text { years old). } 3 \\
\text { participants were } \\
\text { diagnosed with } \\
\text { mild TBI while } 4 \\
\text { participants } \\
\text { demonstrated } \\
\text { borderline } \\
\text { normal. }\end{array}$ & $\begin{array}{l}30 \text { min } \\
\text { sessions of } \\
\text { spaced } \\
\text { retrieval } \\
\text { training } \\
\text { delivered over } \\
\text { the telephone. }\end{array}$ & No comparator & $\begin{array}{l}\text { Spaced } \\
\text { retrieval } \\
\text { data forms }\end{array}$ & $\begin{array}{l}\text { Memory } \\
\text { Achieved } 95.2 \% \\
\text { goals attempted } \\
\text { Self-reported } \\
\text { execution of } \\
76.1 \% \text { goals } \\
8 \text { reports of "far" } \\
\text { generalization to } \\
\text { unrelated } \\
\text { problems } \\
\text { were made. }\end{array}$ \\
\hline
\end{tabular}




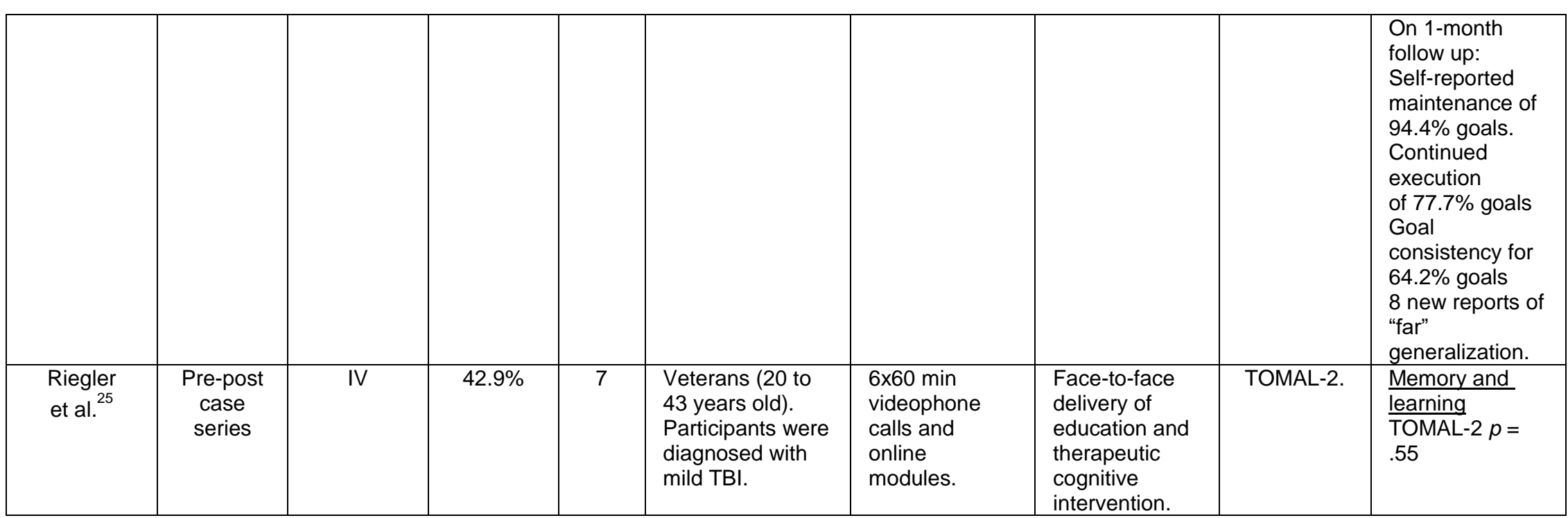

Note: Abbreviations: FIM, Functional Independence Measure; DRS, Disability Rating Scale; GOS-E, Glasgow Outcome Scale (extended); PART-O, Participation with Recombined Tools-Objective; EQ-5D, EuroQol; PQOL, Perceived Quality of Life Scale; SF-12, Short-Form 12 Health Survey; BSI-18, Brief Symptom Inventory-18; BSI-D, Brief Symptom Inventory-Depression; MHI, Mental Health Index; NFI-D, Neurobehavioural Functioning Inventory-Depression; TOMAL-2, Test of Memory and Learning 2nd edition; HAMD-17, 17item Hamilton Depression Rating Scale; SCL-20, Symptom Checklist-20; SCID, Structured Clinical Interview for Diagnostic and Statistical Manual of Mental Disorders, $4^{\text {th }}$ edition; PGI, Patient Global Impression; SF-36, 36-item Short Form Survey; NFI, Neurobehavioural Functioning Inventory; CIQ, Community Integration Questionnaire; CTQ,

Compensatory Techniques Questionnaire. 


\section{Summary of Results}

Table 5 presents the results for cognitive functioning and quality of life for the included studies.

\section{Primary Outcome}

For studies in which the effectiveness of telerehabilitation was investigated for improving memory following TBI, Riegler et al25 found that while there were significant pre-post assessment effects (within group change), there was no significant difference ( $p=$ .55) between clinic-based treatment and Military Online Problem Solving Intervention (MOPS-VI). This finding indicated that irrespective of the intervention, memory and learning improved after treatment for both MOPS-VI and the face-to-face control group. ${ }^{25}$ Similarly, Bergquist et al, 22 who used a cross-over study design, found no significant difference $(p>.05)$ in regard to memory function after 60 sessions of online instant messaging with a therapist to trial a calendar system and the control diary intervention. However, Bergquist et $\mathrm{a}^{22}$ did observe significant improvements in functioning between the baseline and final assessment periods when participants utilized instant messaging while employing the strategy of using calendar notes $(p=.02)$ or using a cue card for compensation techniques $(p=.01)$. Additionally, family members rated participants as having significantly better $\operatorname{mood}(p=.02)$ and fewer memory problems $(p=.04)$ on the NFI at the conclusion of the study compared with their ratings at baseline. ${ }^{22}$ Melton and Bourgeois did not report on statistically significant findings; however, results of the study indicated a high level of success for participants who undertook Spaced Retrieval Training over the telephone in achieving goal mastery (95.2\%), maintenance (94.4\%), and continued execution of goals at follow-up $(77.7 \%) .{ }^{26}$

\section{Secondary Outcomes}

For studies in which the effectiveness of telerehabilitation for depressive symptoms following TBI were investigated, Bombardier et al found the treatment group showed significantly lower overall depressive symptoms for all three outcome measures (BSI-D T scores $p=.017$, NFI-D subscale score $p=.02$, MHI $-5 p=.009$ ) while symptoms in the control group were measured as significantly worse at follow-up on the BSI-D subscale. ${ }^{23}$ This result was in contrast with Fann et al who reported no significant difference between the combined CBT (CBT in-person and CBT via telephone) and standard care groups on the HAMD-17 (treatment effect $=1.2,95 \% \mathrm{Cl}[-1.5-4.0], p=.37$ ), and there was no significant trend favoring CBT on the SCL-20 (treatment effect $=0.28,95 \% \mathrm{Cl}$ [-0.03-0.59], $p=.074) .{ }^{24}$ The CBT-T group had significantly increased improvement on the SCL-20 than the standard care group (treatment effect $=0.36,95 \% \mathrm{Cl}[0.01-0.70], p=.043$ ), and CBT participants reported significantly more symptom improvements $(p=.010)$ and greater satisfaction with depression care $(p<.001)$ than the standard care group. ${ }^{24}$ However, this result does not indicate increased effectiveness of CBT delivered via telephone over CBT delivered in person. ${ }^{24}$ When investigating outcomes related to function and quality of life, Bell et al found no significant differences between intervention and control groups at one- ( $p$ $=.987)$ and two-years $(p=.983)$ follow-up..$^{21}$

Table 5. Summary of Results

\begin{tabular}{|c|c|c|c|c|}
\hline Study & \multicolumn{2}{|c|}{ Primary outcomes } & \multicolumn{2}{c|}{ Secondary outcomes } \\
\hline & Memory & Cognitive functioning and learning & Depressive symptoms & Quality of life \\
\hline Bell et al21 & $\mathrm{NR}$ & $\uparrow^{+}$ & $\downarrow^{+}$ & $\uparrow^{+}$ \\
\hline Bergquist et al22 $^{22}$ & $\uparrow^{+}$ & $\mathrm{NR}$ & $\mathrm{ND}$ & $\mathrm{NR}$ \\
\hline Bombardier et al23 $^{23}$ & $\mathrm{NR}$ & $\mathrm{NR}$ & $\downarrow^{*}$ & $\mathrm{NR}$ \\
\hline Fann et al24 & $\mathrm{NR}$ & $\mathrm{NR}$ & $\mathrm{{ } ^ { + }}$ & $\mathrm{NR}$ \\
\hline Melton \& Bourgeois $^{26}$ & $\uparrow^{+}$ & $\uparrow^{+}$ & $\mathrm{NR}$ & $\mathrm{NR}$ \\
\hline Riegler et al25 & $\uparrow^{+}$ & & $\mathrm{NR}$ \\
\hline
\end{tabular}

Note: Key:

$\mathrm{NR}=$ no results for the outcome measure in the study $\mathrm{ND}=$ no difference between the intervention and control groups $\uparrow=$ increase with intervention
$\downarrow=$ decrease with intervention
${ }^{*}=$ results are statistically significant
$+=$ results are positive for intervention
- = results are not positive for intervention 


\section{NHMRC Body of Evidence Framework}

Table 6 has a synthesis of the results of the 6 included studies using the NHMRC FORM framework. ${ }^{27}$ Despite some consistent evidence to indicate that telerehabilitation may be equally effective as other forms of care, due to variability in baseline characteristics, outcome measures used, sample sizes, comparators, and intervention delivery, care should be taken in its application. Nevertheless, this finding is an important one as it presents another mechanism to provide rehabilitation for people with TBI who may not be able to readily access more traditional forms of treatment for TBI, such as those from rural and remote areas.

\begin{tabular}{|c|c|c|}
\hline \multicolumn{3}{|c|}{ Table 6: NHMRC Body of Evidence Framework } \\
\hline Component & Grade & Comments \\
\hline Evidence base & $\begin{array}{l}\text { C - Satisfactory } \\
\text { One or two level III studies with a } \\
\text { low risk of bias, or level I or II } \\
\text { studies with a moderate risk of bias. }\end{array}$ & $\begin{array}{l}\text { Quantity: Six studies } \\
\text { Level II - three studies } \\
\text { Level III-1 - one study } \\
\text { Level III-2 - one study } \\
\text { Level IV - one study } \\
\text { Quality: Moderate }\end{array}$ \\
\hline Consistency & $\begin{array}{l}\text { C-Satisfactory } \\
\text { Some inconsistency reflecting } \\
\text { genuine uncertainty around clinical } \\
\text { question. }\end{array}$ & $\begin{array}{l}\text { - Consistent study design (RCTs) except } 2 \text { studies (case control } \\
\text { and pre-post case series). } \\
\text { - Baseline statistics showed an imbalance to include more male } \\
\text { participants. } \\
\text { - Two studies did not include baseline statistics. } \\
\text { - Although baseline data was available, not all potential } \\
\text { confounding variables were considered (eg, geographical } \\
\text { location, socioeconomic status). } \\
\text { - Two studies did not account for dropouts. }\end{array}$ \\
\hline Clinical impact & $\begin{array}{l}\text { C-Satisfactory } \\
\text { Moderate }\end{array}$ & $\begin{array}{l}\text { - Four studies were focused on quality of life, and } 3 \text { were } \\
\text { focused on cognitive functioning. } \\
\text { - Two studies did not have a comparator. } \\
\text { - One study showed significant difference in } \\
\text { results. Five studies indicated clinical } \\
\text { importance. }\end{array}$ \\
\hline Generalizability & $\begin{array}{l}\text { C-Satisfactory } \\
\text { Population/s studied in the body of } \\
\text { evidence differ to the target } \\
\text { population guideline, but it is } \\
\text { clinically sensible to apply this } \\
\text { evidence to the target population. }\end{array}$ & $\begin{array}{l}\text { - Populations included were consistent with target population } \\
\text { age range. } \\
\text { - All studies included were from the United States. } \\
\text { - Participants were recruited from hospital or rehabilitation } \\
\text { centers. Three studies had relatively small sample sizes. }\end{array}$ \\
\hline $\begin{array}{l}\text { Grade of } \\
\text { recommendation }\end{array}$ & $\begin{array}{l}\text { C-Satisfactory } \\
\text { Body of evidence presents some } \\
\text { support for recommendation(s) but } \\
\text { care should be taken in its } \\
\text { application. }\end{array}$ & $\begin{array}{l}\text { - Studies were of moderate quality. } \\
\text { - The current evidence base is mixed with discrepancies in } \\
\text { baseline characteristics, study design, differing interventions, } \\
\text { comparators, outcome measures, and sample size. }\end{array}$ \\
\hline
\end{tabular}

\section{DISCUSSION}

In this review, the effectiveness of telerehabilitation was investigated for improving cognitive functioning and quality of life in adults aged 18 to 64 years with mild to severe TBI. Of the 6 studies included, 4 were directed towards improving depressive symptoms and quality of life while 3 were focused on cognitive functioning. Due to a limited evidence base, the methodological quality of the included studies varied significantly. Collectively, there is some consistent evidence to indicate that telerehabilitation may be equally effective as other forms of care in the delivery of cognitive and psychological interventions in addressing memory and depressive symptoms for adults with mild to severe TBI. However, it is unclear if it is superior to other forms of care. 
The findings of this systematic review are supported by similar research in this field. For example, Cicerone et al conducted a systematic review and found consistent evidence to support interventions for attention, memory, and executive functioning following TBI. ${ }^{28}$ Specifically, in terms of improving memory function, cognitive rehabilitation that utilized compensatory strategy training, internalized strategies, and external memory compensations (eg, calendars or notebooks) were recommended for adults with moderate to severe memory impairment. ${ }^{28}$ Elements of these strategies were incorporated into all interventions for memory function that were investigated by the researchers for the studies included in this systematic review.22,25-26 This finding perhaps indicates that irrespective of the mode of delivery as long as the interventions are using cognitive rehabilitation strategies, they are likely to be effective. Similarly, the positive impact of rehabilitation on quality of life presented in this systematic review is supported by Patel et al who demonstrated that patients with mild to severe TBI who received rehabilitation services reported improved quality of life. ${ }^{29}$

There were a number of unique findings from this systematic review that are worth considering. For example, Riegler et al undertook research within the veteran population and identified a range of positive outcomes, which suggests that veterans with TBI may benefit from online treatment programs. ${ }^{25}$ In addition to the positive outcomes, our study also presented that the teletherapy group spent significantly less time in therapy when compared with the standard face-to-face treatment, despite similar outcomes following the study. ${ }^{25}$ Given the increasing recognition for the health and well-being of veterans, our research presented new and innovative models of care when dealing with this population group. Bombardier et al reported improvements in decreasing depressive symptoms through addressing client concerns and facilitating problem-solving skills. ${ }^{23}$ Interestingly, Bombardier et al used motivational interviewing, involving family in the intervention and a behavioral approach that focused on problem solving. ${ }^{23} \mathrm{~A}$ problem-solving approach may be effective for individuals with TBI as poor problem-solving skills and concrete thinking have been found as empirical predictors of depression following TBI. ${ }^{30}$

\section{Parameters of Telerehabilitation}

While there was some consistency with regard to the intervention parameters, there were also differences highlighting no standardized methods of delivery. This issue is an important one to consider as the variability in how the telerehabilitation was delivered may have had an impact on patient outcomes. For example, Fann et al demonstrated that the more sessions completed by individuals, the better they scored on the SCL-20 with 8 or more sessions being predictive of improved results. ${ }^{24}$ Similarly, participants in the study by Bombardier et al completed 7 telephone sessions over the first year following TBI, which resulted in improved outcomes on all depressive symptom measures, compared with those who received usual care. ${ }^{23}$ However, not all studies had a dose-response. Bell et al recognized that those who received more telephone contacts generally had a more favorable prognostic profile, indicating participants who will experience better outcomes are also more likely to be available for telephone contact. ${ }^{21}$ Such variability of intervention parameters is not uncommon within the telerehabilitation literature. For example, Fridler et al, who investigated telerehabilitation for aphasic patients, reported that undertaking 14 therapy sessions twice to 3 times a week resulted in skills improvement and beneficial effects for aphasia patients. ${ }^{31}$ Moffet et al, who investigated telerehabilitation delivered in 16 sessions over 2 months for patients following a total knee arthroplasty, found significant variability in results of decreasing pain, stiffness, and improving function. ${ }^{32}$ In another systematic review, Johansson and Wild reported on telerehabilitation for stroke and found the length of interventions of the included studies varied from 4 to 6 weeks with a 1-hour session 5 days per week showing improvement in upper extremity function. ${ }^{33}$ Hence, as can be seen through these examples, there is a significant lack in research for exploring parameters for telerehabilitation across different conditions. Given such heterogeneity as found in this systematic review, future research could explore the ideal parameters for telerehabilitation for TBI.

As telerehabilitation also has a focus on improving access to health care, the accessibility of telerehabilitation for adults with TBI was also explored. Melton and Bourgeois ${ }^{26}$ reported that overall attendance rates were $84.4 \%$ while Riegler et al25 reported that $67 \%$ of veterans initially non-adherent to clinic-based treatment adhered to telerehabilitation. This finding may suggest that telerehabilitation is a feasible alternative for treatment as it may be convenient and more accessible for patients in which compliance with traditional treatment settings may not be possible (such as travel costs). This finding is supported by findings from the literature. Researchers exploring depression treatment preferences among people with TBI identified that $72.4 \%$ of participants indicated that they would be likely to participate in a telephone-based intervention, and $30.6 \%$ of participants reported that would be likely to participate in an Internet-based intervention. ${ }^{34}$

However, telerehabilitation is not without its limitations, especially in the form of technological and logistical issues. Bombardier et al ${ }^{23}$ reported that calls were missed due to failure to connect despite multiple attempts while Bell et al ${ }^{21}$ reported that when participants were called on mobile phones, some participants were in public places and distracted during the intervention. Additionally, Bell et al highlighted that some practitioners may be uncomfortable with the use of telephones as a treatment modality as they are not exposed to this modality in their training and may struggle to compensate for the loss of visual cues in interactions with their clients. ${ }^{21}$ Therefore, it is important to recognize these 
limitations, address such practical issues upfront, and ensure that strategies are put in place before telerehabilitation is integrated into standard care for TBI.

\section{Limitations}

As with any research, this systematic review has some limitations. While 4 of the 6 included studies were RCTs, the evidence base has a number of methodological issues that require consideration. These issues include allocation bias due to lack of sufficient detail regarding the randomization process; attrition bias due to withdrawals and dropouts; and performance bias and placebo bias due to lack of blinding of the participants, health professionals, and researchers. ${ }^{25,26}$ In 2 studies, there was baseline imbalance bias as $75 \%$ of the participants were male; however, this factor may be due to a higher incidence of TBI in men. ${ }^{21,23}$ Reporting bias was also likely in 2 studies as the baseline characteristics of each intervention group were not provided.24,25 As with any rehabilitation research, the potential influence of the Hawthorne effect across all studies must be recognized as it was difficult to distinguish the influence of the personal characteristics of the health professionals delivering the intervention and their relationship with the participants from the true effect of the intervention. The focus of this systematic review only was on adults of a specific age range (18 to 64 years), so these findings may not be generalizable to pediatric or geriatric populations with this condition. The focus of this review was also specifically on cognitive functioning and quality of life as outcomes as the impact of cost was not analyzed. This factor is important to consider as telerehabilitation does require extensive resource allocation and cost. Despite a comprehensive search strategy, only English-language articles were included in this systematic review, so potential for language bias should be acknowledged. While grey literature was searched, this search was limited to one search engine (Google), which resulted in some publication bias.

\section{CONCLUSIONS}

\section{Implications for Clinical Practice}

There is consistent evidence to indicate that telerehabilitation may be equally effective but not superior to other forms of care in improving cognitive functioning and quality of life in adults with TBI. Although the evidence base is limited, this recommendation is derived from studies of moderate methodological quality of which 4 of the 6 included studies were RCTs.

Telerehabilitation incorporates specific interventions, such as CBT or educational and training strategies, which may result in positive outcomes. Therefore, it appears that telerehabilitation may be a viable approach for service delivery for patients with TBI who may have personal disability or geographic barrier to access health services. Given the tyranny of distance that is encountered across a country the size of Australia, telerehabilitation may offer improved access to services for patients with TBI who are living in rural and remote areas without compromising health care outcomes. Given the issues with regard to availability of and access to technology, factors such as financial costs and patient preferences should be considered when utilizing telerehabilitation as a complementary treatment with traditional forms of rehabilitation for patients with TBI.

\section{Implications for Future Research}

Given the heterogeneity of the telerehabilitation parameters, it is difficult to ascertain the most effective type, frequency, intensity, and duration. This diversity also results in varied treatment effects, which makes comparisons difficult. Therefore, future research would benefit from studies in which the focus is on developing standardized intervention parameters. Given that similar heterogeneity persists with regard to outcome measurement, future research should also be focused on the development of standardized outcome measures for TBI. Finally, methodologically sound RCTs that are conducted with larger sample sizes with representative samples and inclusive of cost-benefit analysis would assist in identifying the impact of telerehabilitation for patients with TBI. 


\section{REFERENCES:}

1. Menon DK, Schwab K, Wright DW, Maas Al; Demographics and Clinical Assessment Working Group of the International and Interagency Initiative toward Common Data Elements for Research on Traumatic Brain Injury and Psychological Health. Position statement: definition of traumatic brain injury. Arch Phys Med Rehabil. 2010 Nov;91(11):1637-1640. [PMID: 21044706]

2. Beck B, Bray JE, Cameron PA, Cooper DJ, Gabbe BJ. Trends in severe traumatic brain injury in Victoria, 2006-2014. Med J Aust. 2016;204(11):1-6. [PMID: 27318397]

3. Hwang HF, Cheng CH, Chien DK, Yu WY, Lin MR. Risk factors for traumatic brain injuries during falls in older persons. J Head Trauma Rehabil. 2015;30(6):E9-17. [PMID: 25629257]

4. Rosenfeld JV, Maas Al, Bragge P, Morganti-Kossmann MC, Manley GT, Gruen RL. Early management of severe traumatic brain injury. Lancet. 2012;380(9847):1088-1098. [PMID: 22998718]

5. Draper K, Ponsford J. Cognitive functioning ten years following traumatic brain injury and rehabilitation. Neuropsychology. 2008;22(5):618-625. [PMID: 18763881]

6. Padula W. Mild traumatic brain injury (mTBI): Symptoms without evidence. J Neurol Sci. 2016;370:303-4. [PMID: 27637374]

7. Lin L, Liou T, Hu C, Ma H, Ou J, et al. Balance function and sensory integration after mild traumatic brain injury. Brain Inj. 2015;29(1):41-46. [PMID: 25265292\}

8. Friedland J. Improving the classification of traumatic brain injury: The Mayo classification system for traumatic brain injury severity. J Spine. 2013;4(5):1-3.

9. Khan F, Baguley IJ, Cameron ID. Rehabilitation after traumatic brain injury. Med J Aust. 2003;178(6):290-295. [PMID: 12633489]

10. Turkstra L, Quinn-Padron M, Johnson J, Workinger M, Antoniotti N. In-person versus telehealth assessment of discourse ability in adults with traumatic brain injury. J Head Trauma Rehabil. 2012;27(6):424-432. [PMID: 22190010]

11. SA Health. Telerehabilitation. Government of South Australia. September 2017. Available at: http://www.sahealth.sa.gov.au/ wps/wcm/connect/public+content/sathealth+internet/health+services/rehabilitation+services/telerehabilitation. Accessed September 12, 2017.

12. Moher $D$, Liberati A, Tetzlaff J, Altman DG. Preferred reporting items for systematic reviews and meta-analyses: the PRISMA statement. J Clin Epidemiol. 2009;62(10):1006-1012. [PMID: 19631508]

13. Wheeler S, Acord-Vira A, Davis D. Effectiveness of interventions to improve occupational performance for people with psychosocial, behavioral, and emotional impairments after brain injury: a systematic review. Am J Occup Ther. 2016;70(3):19. [PMID: 27089290]

14. Kreutzer J, Seel R, Marwitz J. The Neurobehavioral Functioning Inventory. San Antonio, TX: The Psychological Corporation; 1999.

15. Randolph C. RBANS Manual: Repeatable Battery for the Assessment of Neuropsychological Status. San Antonio, TX: The Psychological Corporation; 1998.

16. EuroQol Group. EuroQol-a new facility for the measurement of health-related quality of life. Health Policy. 1990;16(3):199208. [PMID: 10109801]

17. Hamilton M. A rating scale for depression. J Neurol Neurosurg Psychiatry. 1960;23(1):52-62.

18. National Health and Medical Research Council. NHMRC Additional Levels of Evidence and Grades for Recommendations for Developers of Guidelines. Australian Government. 2009. Available at: https:// www/nhmrc.gov.au/_files_nhmrc/file/guidelines/ developers/nhmrc_levels_grades_evidence_120423.pdf. Accessed August 12017.

19. Critical Appraisal Skills Programme (CASP). Randomised Controlled Trials Checklist. CASP UK. May 31, 2013. Available at: http://docs.wixstatic.com/ugd/dded87_4239299b39f647ca9961f30510f52920.pdf. Accessed July 14, 2017.

20. Law M, Stewart D, Pollock N, Letts L, Bosch J, Westmorland M. Critical Review Form-Quantitative Studies. Hamilton, ON: McMaster University; 1998. Available at: https://srs-mcmaster.ca/wp-content/uploads/2015/04/Critical-Review- FormQuantitative-Studies-English.pdf. Accessed July 14, 2017.

21. Bell KR, Brockway JA, Hart T, Whyte J, Sherer M, et al. Scheduled telephone intervention for traumatic brain injury: a multicenter randomized controlled trial. Arch Phys Med Rehabil. 2011;92(10):1552-1560. [PMID:21963122]

22. Bergquist T, Gehl C, Mandrekar J, Lepore S, Hanna S, et al. The effect of internet-based cognitive rehabilitation in persons with memory impairments after severe traumatic brain injury. Brain Inj. 2009;23(10):790-799. [PMID: 19697167]

23. Bombardier CH, Bell KR, Temkin NR, Fann JR, Hoffman J, Dikmen S. The efficacy of a scheduled telephone intervention for ameliorating depressive symptoms during the first year after traumatic brain injury. J Head Trauma Rehabil. 2009;24(4):230238. [PMID: 19625862]

24. Fann JR, Bombardier CH, Vannoy S, Dyer J, Ludman E, et al. Telephone and in-person cognitive behavioral therapy for major depression after traumatic brain injury: a randomized controlled trial. J Neurotrauma. 2015;32(1):45-57. [PMID: 25072405]

25. Riegler LJ, Neils-Strunjas J, Boyce S, Scheifele PM, Wade SL. Cognitive intervention results in web-based videophone treatment adherence and improved cognitive scores. Med Sci Monit. 2013;19(1):269-275. [PMID: 23584165] 
26. Melton A, Bourgeois M. Training compensatory memory strategies via the telephone for persons with TBI. Aphasiology. 2005;19(3-5):353-364.

27. Hillier S, Grimmer-Somers K, Merlin T, Middleton P, Salisbury J, et al. FORM: An Australian method for formulating and grading recommendations in evidence-based clinical guidelines. BMC Med Res Methodol. 2011;11(23):1-8. [PMID: 21356039]

28. Cicerone KD, Langenbahn DM, Braden C, Malec JF, Kalmar K, et al. Evidence-based cognitive rehabilitation: updated review of the literature from 2003 through 2008. Arch Phys Med Rehabil. 2011;92(4):519-530. [PMID:21440699]

29. Patel MB, Wilson LD, Bregman JA, Leath TC, Humble SS, et al. Neurologic functional and quality of life outcomes after TBI: clinic attendees versus non-attendees. J Neurotrauma. 2015;32(13):984-989. [PMID: 25683481]

30. Leon-Carrion J, De Serdio-Arias MA, Murillo Cabezas F, Dominguez Roldan JM, Dominguez-Morales R, et al. Neurobehavioral and cognitive profile of traumatic brain injury patients at risk for depression and suicide. Brain Inj. 2001;15(2):175-181. [PMID: 11260767]

31. Fridler N, Roden K, Herzberg O, Lev A, Kaplan D, et al. Tele-rehabilitation therapy vs. face-to-face therapy for aphasic patients. The Fourth International on eHealth, Telemedicine, and Social Medicine. 2012Jan;18-23.

32. Moffet $H$, Tousignant M, Nadeau S, Merette C, Boissy $P$, et al. In-home telerehabilitation compared with face-to-face rehabilitation after total knee arthroplasty: a noninferiority randomized controlled trial. J Bone Joint Surg Am. 2015;97(14):1129-1141. [PMID: 26178888]

33. Johansson T, Wild C. Telerehabilitation in stroke care-a systematic review. J Telemed Telecare. 2011;17(1):1-6. [PMID: 21097560]

34. Fann JR, Jones AL, Dikmen SS, Temkin NR, Esselman PC, Bombardier CH. Depression treatment preferences after traumatic brain injury. J Head Trauma Rehabil. 2009;24(4):272-278.[PMID: 19625866] 


\section{APPENDIX}

\begin{tabular}{|c|c|c|c|c|c|c|}
\hline \multicolumn{7}{|c|}{ Table A-1: Medline Search Strategy } \\
\hline \multirow[t]{2}{*}{ E-database } & \multicolumn{4}{|c|}{ Search terms } & \multirow[t]{2}{*}{ Limits } & \multirow[t]{2}{*}{ Specifications } \\
\hline & $\underline{P}$ & $\underline{1}$ & $\underline{C}$ & $\underline{0}$ & & \\
\hline Medline & $\begin{array}{l}\text { Brain injuries/ } \\
\text { Traumatic/ Brain } \\
\text { concussion/ Brain } \\
\text { Contusion/ } \\
\text { trauma* brain injur* } \\
\text { or brain injur* or } \\
\text { brain trauma* or } \\
\text { TBI* or brain } \\
\text { concussion* or } \\
\text { cerebral } \\
\text { concussion* }\end{array}$ & 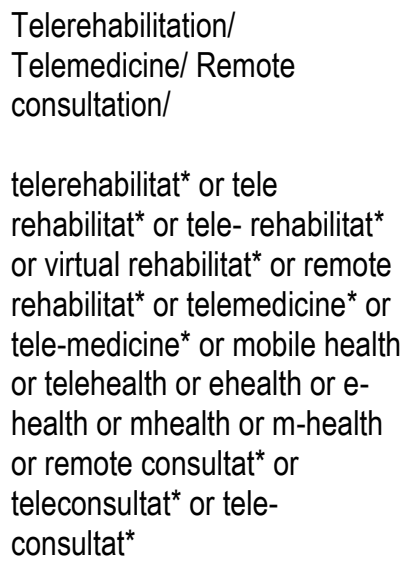 & $\begin{array}{l}\text { No compa } \\
\text { be used in }\end{array}$ & $\begin{array}{l}\text { me to } \\
\text { egy }\end{array}$ & $\begin{array}{l}\text { Humans, } \\
\text { English language, all } \\
\text { adult (19 plus years) }\end{array}$ & $\begin{array}{l}\text { MeSH headings, key } \\
\text { words, truncation }\end{array}$ \\
\hline
\end{tabular}

Legend: * = truncation; / = MeSH heading; Booleans: "or" in between keywords in the same column, "and" used to add each column's PICO components 